\title{
A method of identifying effective source rocks and its application in the Bozhong Depression, Bohai Sea, China
}

\author{
Jiang Fujie ${ }^{1,2 *}$, Pang Xiongqi ${ }^{1,2}$, Meng Qingyang ${ }^{3}$ and Zhou Xiaohui ${ }^{1,2}$ \\ ${ }^{1}$ Basin and Reservoir Research Center, China University of Petroleum, Beijing 102249, China \\ ${ }^{2}$ State Key Laboratory of Petroleum Resource and Prospecting, Beijing 102249, China \\ ${ }^{3}$ Research Institute of Petroleum Exploration and Development, PetroChina, Beijing 100083, China \\ (C) China University of Petroleum (Beijing) and Springer-Verlag Berlin Heidelberg 2010
}

\begin{abstract}
Research on effective source rocks directly affects the accuracy of identifying hydrocarbon resources, and indirectly affects the exploration decisions in petroliferous basins. Although the previous evaluation methods of effective source rocks vary relatively widely, a complete quantitative evaluation approach has not yet been developed. For that reason, we redefined the concept of effective source rocks based on the existing research results. Surrounding this definition, and guided by the hydrocarbon expulsion theory, the quantitative model called "two stages and three steps" method is established to predict effective source rocks. Its application in the Bozhong Depression indicates that among the four sets source rocks in the Bozhong Depression, the Member 3 of the Shahejie Formation $\left(\mathrm{Es}_{3}\right)$ has the largest effective source rock thickness, and the Member 1-Member 2 of the Shahejie Formation $\left(\mathrm{Es}_{1+2}\right)$ is the second largest .The effective part of dark mudstone is only $30 \%-80 \%$ of the total volume and with the increase of buried depth and improvement of quality, the effective part increases. Comprehensive analysis indicates that the "two stages and three steps" method is a practical technique for effective source rock prediction.
\end{abstract}

Key words: Source rock, effectiveness, hydrocarbon expulsion threshold, Bozhong Depression, Bohai Sea

\section{Introduction}

Study of effective source rocks is needed for an accurate understanding of petroleum resources potential in the research field. Therefore, a lot of research has been done and some recognition has been achieved, but a complete quantitative assessment system for effective source rocks has not yet been established. In this paper, based on previous research results and the theory of the hydrocarbon expulsion threshold, a set of new methods for identification of effective source rocks are proposed.

\section{Research status of effective source rock}

\subsection{Definition of effective source rock}

Source rock is the first requirement for hydrocarbon accumulation, and the field has been studied by many scholars. Tissot and Welte (1978) put forward the concept of source rock and defined it as the rock that had generated

*Corresponding author. email: jfjhtb@163.com

Received July 29, 2009 or used to be able to generate petroleum. Momper (1978) defined effective source rock as the mother rock which can generate and expel commercial petroleum. Jones (1981) deemed that effective mother rock is the source for a commercial reservoir determined by reliable oil-source correlation. In the natural environment, any kind of finegrained sediment that has generated and expelled enough hydrocarbons to form a commercial oil and gas accumulation could be reckoned as source rock (Hunt, 1979). Sheng (1989) classified effective source rock as that part of mature source rock that can expel or diffuse generated hydrocarbon. Li et al (1999) defined effective gas source rock as the sedimentary rock that can generate enough gas under suitable thermal maturation conditions and expel gas to form gas pools after the pore and surface of the source rock had been completely saturated. Jin (2001) defined effective source rock as the strata that had generated and expelled oil and gas, and to some extent controlled the distribution of hydrocarbon accumulations in sedimentary basins. Jiang et al (2002) proposed that source rock was effective only when it could expel enough hydrocarbons to compensate for all kinds of losses in the process of reservoir formation and form commercial hydrocarbon accumulations. Rao et al (2003) 
thought that effective source rock should be source rock that has been shown by reliable oil-source correlation to have formed commercial hydrocarbon accumulations. Wang et al (2003) defined effective source rock as the rock that could both generate and expel hydrocarbon.

In this paper, the core of effective source rock identification is focused on whether hydrocarbon had been generated and expelled or not. Whether the expelled hydrocarbon is enough to form a commercial hydrocarbon pool or not must be determined by exploration degree and is hard to identify. Moreover, when there were several sets of source rocks, although some source rocks did not expel a large amount of hydrocarbon, which was thoroughly dispersed during secondary migration but which protected against further losses of hydrocarbon expelled from other source rocks, they should also be taken as effective source rocks for their contribution to hydrocarbon accumulation. Therefore, the concept of effective source rock should be defined as the strata that have generated and expelled hydrocarbon in the process of geologic evolution.

\subsection{Traditional research methods}

Geochemical index correlation is generally adopted for studying effective source rocks, and organic matter abundance is usually used as an identification yardstick. Organic matter abundance is often indicated by the total organic carbon (TOC) content, chloroform asphalt A and total hydrocarbon, among which the organic carbon content controls the characteristics of the other two factors. So organic carbon content is often taken as the minimum value of effective source rock (Barker, 1974; Cheng, 1982; Xia and Dai, 2000; Li, 2003; Teng et al, 2004; Chen et al, 2004; Chen, 2005; Zhang et al, 2006; 2007). The minimum value of organic matter abundance for an effective source rock differs from $0.05 \%$ to $1 \%$ according to previous research (Barker, 1974; Tissot and Welte, 1978; Hunt, 1979; Cheng, 1982; Fu et al, 1983; Xia and Dai, 2000), which is artificially limited by practical measurements and brings great uncertainty on effective source rock identification and assessment. In addition, other methods such as the physical simulation method (Lewan and Williams, 1987; England et al, 1987; Wang and Wang, 1999; Jin et al, 2001; Xiong, 2001) and observation of hydrocarbon content from close sampling are also applied to study source rock effectiveness (Leythaeuser et al, 1988; Zhou and Zhang, 1999). However, restrained by coring, experimental expense, sample amount and experiment conditions, the research results of all the above methods differ a lot with the practical geological conditions. Moreover, due to differences in sedimentary environments and later evolution, source rock can be very heterogeneous (Bertrand et al, 1994; Derenne et al, 2000; Carroll and Bohacs, 2001; Zhu et al, 2003; Zhu and Jin, 2002), which will also affect the research results. As well, the inorganic geochemistry index is also adopted to explore the formation environment of effective source rock. Because a large number of parameters are required in this method, it is hard to use (Teng et al, 2005).

To sum up, the identification of effective source rock still relies upon qualitative identification of a minimum value of organic abundance, and identification methods are mostly proved by practical measurement data and simulation experimental results. A set of quantitative assessment system has not yet been established.

\section{New methods of identifying effective source rocks}

A source rock could be defined as effective, only when hydrocarbon has been generated and expelled to reservoir strata. So simply identifying the minimum value of organic abundance is not enough to define the characteristics of effective source rock. Besides, even if the source rock has generated hydrocarbon, but it is still residual in the source rock and has not been expelled outside, the source rock is not effective at all. All the problems above can not be solved by previous research methods. In view of the problems, a set of effective source rock identification methods are explored in this paper, which is temporarily called "two stages and three steps" method. The main process is as follows:

(1) Stage 1: Geological statistics stage

Step 1: In this stage, the main task is to collect statistics on the thickness of dark mudstone (shale) from exploration wells (Fig. 1(a)), and establish a database in the study area. The distribution characteristics of dark mudstone can be mapped horizontally from exploration well logs combined with sedimentary facies, organic facies or seismic inversion data (Zhang et al, 2007).

(2) Stage 2: Geological analysis stage

In this stage, on the basis of geological statistics, geochemical methods are applied to assess the quality of source rock and to identify the thickness of effective source rock from dark mudstone, which can be accomplished in two steps:

Step 2: According to hydrocarbon expulsion threshold theory (Pang, 2003), the effective dark mudstone thickness can be estimated by eliminating that part of the dark mudstone which has not entered the hydrocarbon expulsion threshold.

The hydrocarbon expulsion threshold is a critical geological condition in the burial history, when a separate hydrocarbon phase can be expelled from the source rock, whose hydrocarbon generation amount is more than all that adsorbed by the source rock itself, dissolved in the pore water, dissolved in the oil and retained by capillary forces (Pang, 1995). Only when the dark mudstone enters the hydrocarbon expulsion threshold can hydrocarbon be expelled. The hydrocarbon generation potential method can be adopted to identify the dark mudstone. The theoretical basis of the hydrocarbon generation potential method is material balance, which means the quantity of organic matter in source rock before hydrocarbon generation and expulsion equals to that remained in the source rock plus the part that has evolved into hydrocarbon which is later expelled from the source rock after it enters the hydrocarbon generation and expulsion threshold during the increase of the burial depth (Zhou and Pang, 2002; Jiang et al, 2007). As for the organic matter which could be transformed into hydrocarbon in the source rock, the total amount of material should be constant if no material exchange happened in geological history. During the quantitative assessment of source rock pyrolysis, the 
sum of dissolved hydrocarbon $\left(S_{1}\right)$ and cracked hydrocarbon $\left(S_{2}\right)$ is usually adopted to represent the generation potential of the source rock. In practical application, the hydrocarbon generation potential is represented by the hydrocarbon generation potential index $\left(S_{1}+S_{2}\right) /$ TOC, the decrease of which demonstrated the expulsion of hydrocarbon (Fig. 1(b)). So a dark mudstone that has not entered the hydrocarbon expulsion region can be easily eliminated after the hydrocarbon expulsion threshold is identified.

Step 3: Comprehensive analysis of the effectiveness of dark mudstones which have entered the hydrocarbon expulsion region according to the hydrocarbon expulsion threshold chart.

Because of the high heterogeneity of the organic matter in source rocks, some dark mudstone with low organic matter abundance can not expel hydrocarbon although it has reached the hydrocarbon expulsion threshold. So the hydrocarbon expulsion threshold chart can be applied to calibrate the abundance of organic matter. That is, according to the relation between organic matter abundance and evolution degree, the thickness of effective source rock can be obtained by eliminating the poor quality dark mudstone which is unable to expel hydrocarbon even after it has entered the hydrocarbon expulsion region (Fig. 1(c)). The horizontal distribution of effective source rock thickness can be obtained by calibrating and mapping of the data in the whole area using the ratio of the thickness of obtained effective source rocks to the formation thickness from exploration wells. In this paper, the Source Rock Index (SRI) chart is mainly adopted (Pang et al, 2005). The geological meaning of SRI is the percentage of practical expulsion quantity of hydrocarbon from the source rock compared to that from total high quality source rocks. The SRI value that is less than zero, equals to zero, and is more than zero respectively corresponds to non-hydrocarbon source rocks, threshold source rocks and effective source rocks. The larger the SRI value, the better quality the source rock (Fig. 1(c)). The related calculation approach is described by Pang et al (2005).

\section{Prediction of the thickness of effective source rock in the Bozhong Depression}

\subsection{Regional geological setting}

The Bozhong Depression, the largest depression enriched in hydrocarbon in the Bohai Sea area (Zhang, 2000), lies in the major deep place of the Bozhong sub-basin and extends in a north-east direction with an area of about $8,660 \mathrm{~km}^{2}$. Presently the largest burial depth of the depression basement has exceeded $12,000 \mathrm{~m}$. There are about $38 \times 10^{8} \mathrm{~m}^{3}$ oil and $2,500 \times 10^{8} \mathrm{~m}^{3}$ gas in geological reserves discovered in the Bohai Sea area, which shows a favorable exploration future (Zhu et al, 2000; Zhu and Ge, 2001). Most of the discovered oil and gas fields are distributed in the zone surrounding the Bozhong Depression (Gong et al, 2000). As the largest hydrocarbon generation and enrichment depression of the Bohai Sea area, the resource potential of the Bozhong Depression will directly affect exploration prospects and programs. Accurate identification of source rocks will undoubtedly be the basic guarantee for the understanding of resource evaluation.

\subsection{Prediction of the thickness of effective source rocks}

There are four main sets of source rocks developed in the Bozhong Depression. These are Member 2 of the Dongying Formation $\left(\mathrm{Ed}_{2}\right)$, Member 3 of the Dongying Formation $\left(\mathrm{Ed}_{3}\right)$, Member $1-$ Member 2 of the Shahejie Formation $\left(\mathrm{Es}_{1+2}\right)$ and Member 3 of the Shahejie Formation $\left(\mathrm{Es}_{3}\right)$ in the Paleogene. According to previous work, the thickness of source rock in the Shahejie Formation is much thinner than that of the Dongying Formation, while the reserves of the Shahejie Formation is much larger than that of the Dongying Formation. Whether this is right or not will directly affect exploration directions. In this paper, the "two stages and three steps" method is adopted to initially predict the effective thickness of the four sets of source rocks.

\subsubsection{Distribution characteristics of the dark mudstone thickness}

According to the principles of the "two stages and three steps" method to identify effective source rocks, the thickness statistics of dark mudstone are firstly collected from all the exploration wells in the Bozhong Depression and its surrounding uplifts (Table 1). From the thickness distribution of the dark mudstone in the typical wells, the average thickness of the $\mathrm{Ed}_{2}$ is $115 \mathrm{~m}$, and the maximum thickness in a single well is $430 \mathrm{~m}$. The average thickness of the $\mathrm{Ed}_{3}$ is $150 \mathrm{~m}$. The thickness of the $\mathrm{Es}_{1+2}$ is $10-230 \mathrm{~m}$ and the average value is $65 \mathrm{~m}$. The thickness of the $\mathrm{Es}_{3}$ is $5-200 \mathrm{~m}$ and the average value is $55 \mathrm{~m}$.

For the area in the center of the depression without exploration wells drilled, the corresponding relationship between the ratio of dark mudstone thickness to strata thickness and sedimentary facies is adopted, on the basis of source rock prediction mapping in the low-explored area (Zhang et al, 2007), to horizontally predict the thickness of dark mudstone (Fig. 2). From the overall distribution trend of dark mudstone, the thickness of Ed is significantly more than that of Es, as the sedimentation center of the Bohai Bay Basin migrated during the sedimentation period of Es and Ed (Hou et al, 2000).

\subsubsection{Horizontal distribution characteristics of effective source rock thickness}

Step 1: Analysis of dark mudstone thickness exceeding the hydrocarbon expulsion threshold

According to the basic theory of hydrocarbon generation potential to identify the expulsion threshold, 546 pyrolysis data points from the exploration wells and complementary well test samples were gathered to obtain the expulsion threshold of each interval (Fig. 3). On the basis of the hydrocarbon expulsion threshold depth, the part of the dark mudstone which has not yet entered the hydrocarbon expulsion region is directly omitted, thus the part of dark mudstone which has entered the hydrocarbon expulsion region is acquired in each interval. According to the depth of the hydrocarbon expulsion threshold, the thickness of the dark mudstone which has not entered the hydrocarbon expulsion threshold can be directly eliminated, and then the thickness of mudstone within the hydrocarbon expulsion region can be 

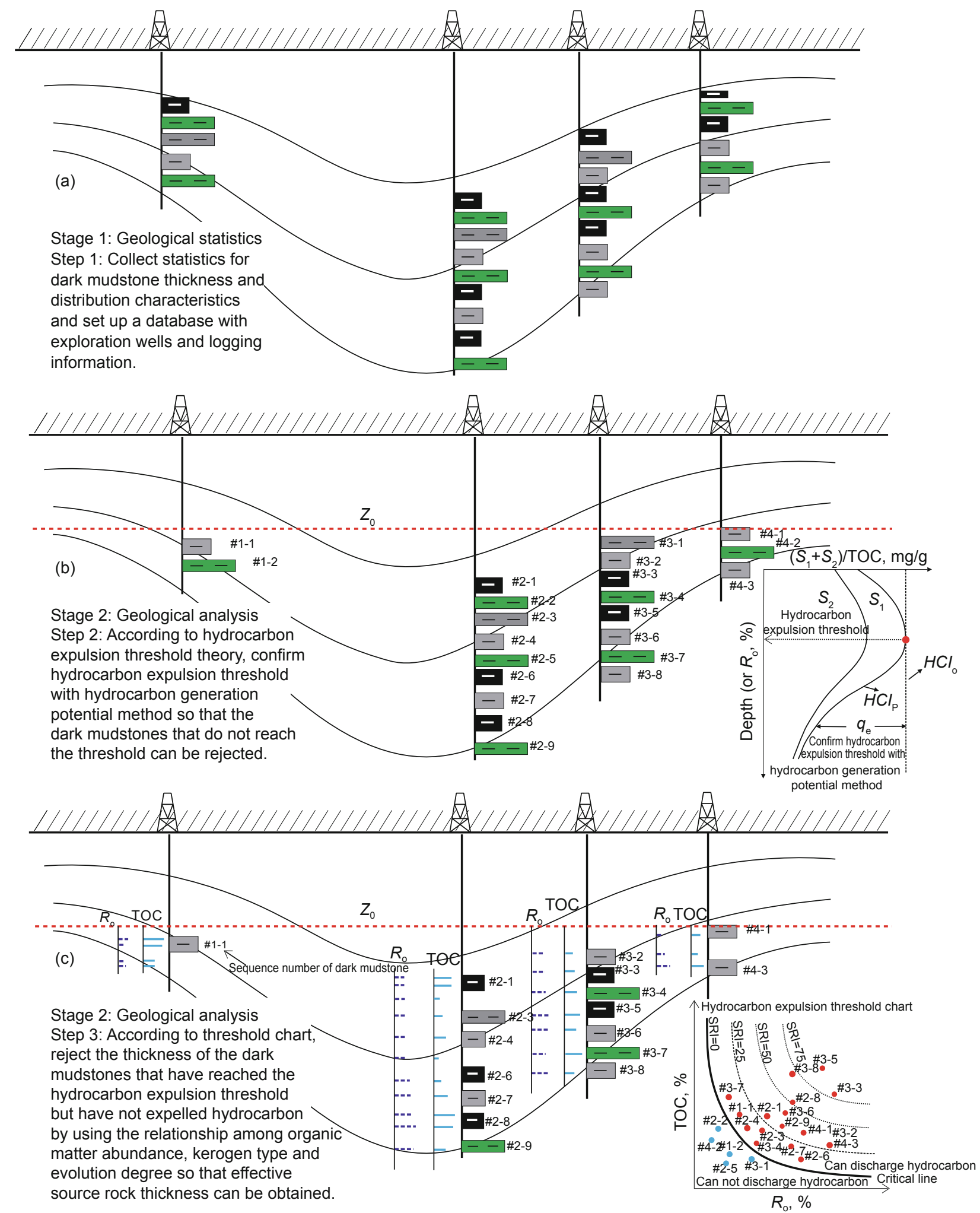

Fig. 1 Chart of "two stages and three steps" method to predict effective source rocks

calculated.

Step 2: Identification of dark mudstone without hydrocarbon expulsion using the hydrocarbon expulsion threshold chart

Statistics on typical wells with overall geochemical data and lithological profile can be used to set up a practical identification chart for hydrocarbon expulsion in different intervals (Fig. 4), and to identify all dark mudstone intervals which have reached the hydrocarbon expulsion depth. Combined with the dark mudstone data exceeding the hydrocarbon expulsion threshold in Step 1, the ratio of the effective source rock thickness to the dark mudstone thickness in different intervals can be obtained (Table 2). According to the distribution characteristics of dark mudstone, the planar distribution characteristics of effective source rock in the Bohai Sea area can be identified (Fig. 5). 
Table 1 Ratio of dark mudstone thickness to formation thickness of different sedimentary types in the Bozhong Depression and its periphery

\begin{tabular}{|c|c|c|c|c|c|}
\hline \multirow{2}{*}{$\begin{array}{c}\text { Formation } \\
\text { name }\end{array}$} & \multirow{2}{*}{ Sedimentary type } & \multicolumn{4}{|c|}{$\begin{array}{l}\text { Ratio of dark mudstone thickness to } \\
\text { formation thickness, } \%\end{array}$} \\
\hline & & Minimum value, $\mathrm{m}$ & Maximum value, $\mathrm{m}$ & Average value, $\mathrm{m}$ & Number of samples \\
\hline \multirow{4}{*}{$\mathrm{Ed}_{2}$} & Braided river delta & 6.8 & 64.5 & 39.4 & 5 \\
\hline & Shore and shallow lake & 5.7 & 90.9 & 47.6 & 21 \\
\hline & Deep lake & 53.6 & 94.7 & 78.3 & 9 \\
\hline & Meandering river delta & 0.7 & 52.5 & 29.4 & 5 \\
\hline \multirow{4}{*}{$\mathrm{Ed}_{3}$} & Braided river delta & 4.3 & 53.4 & 42.9 & 8 \\
\hline & Shore and shallow lake & 35.7 & 80.9 & 48.6 & 12 \\
\hline & Deep lake & 55.2 & 97.6 & 88.6 & 6 \\
\hline & Meandering river delta & 0.7 & 22.5 & 12.4 & 3 \\
\hline \multirow{3}{*}{$\mathrm{Es}_{1+2}$} & Braided river delta & 7.9 & 61.3 & 38.5 & 4 \\
\hline & Shore and shallow lake & 56.2 & 98.6 & 52.7 & 6 \\
\hline & Deep lake & 55.2 & 97.6 & 88.6 & 6 \\
\hline \multirow{3}{*}{$\mathrm{Es}_{3}$} & Braided river delta & 12.5 & 85.6 & 53.7 & 3 \\
\hline & Shore and shallow lake & 58.4 & 92.5 & 88.5 & 3 \\
\hline & Deep lake & 66.2 & 66.2 & 66.2 & 1 \\
\hline
\end{tabular}

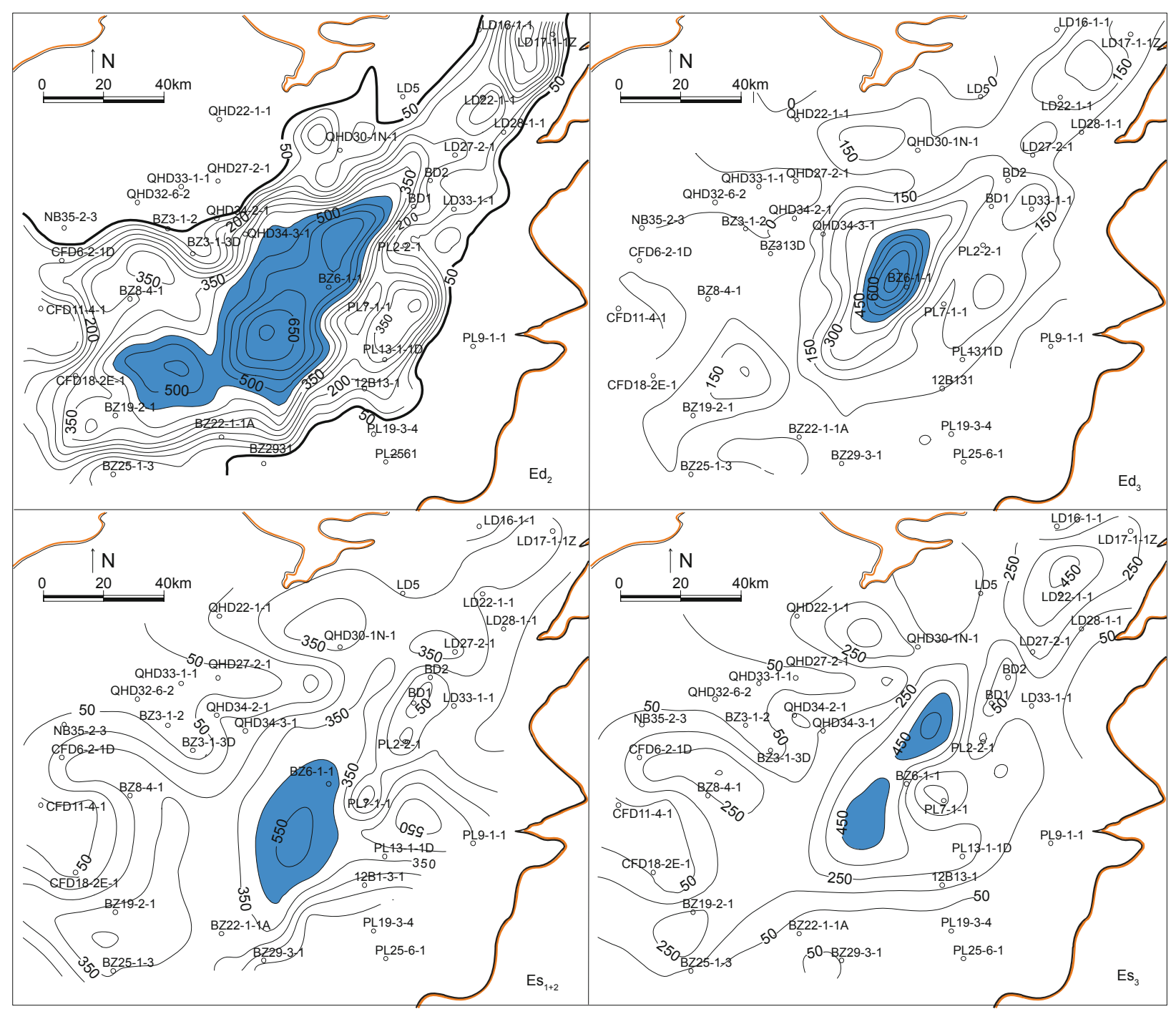

Fig. 2 Contour diagram of dark mudstone thickness of all intervals in the Bozhong Depression 

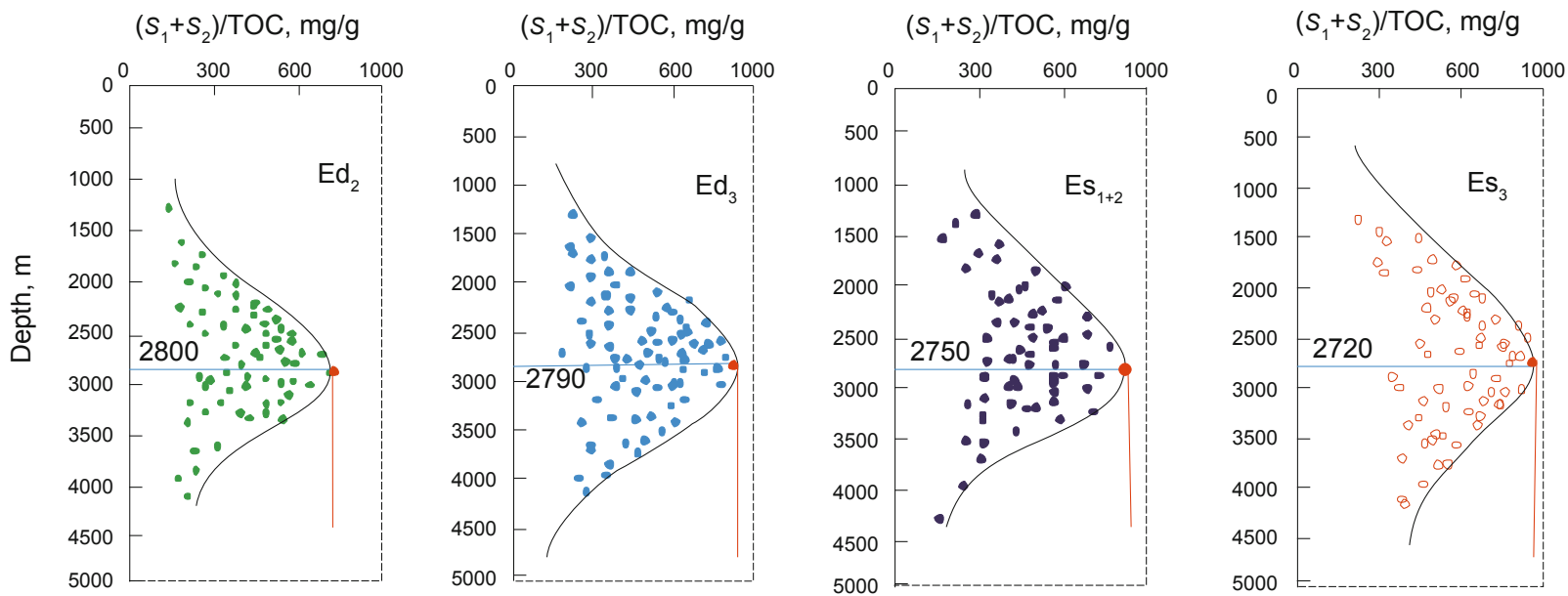

Fig. 3 Depth map of the hydrocarbon expulsion thresholds of Eogene source rocks in the Bozhong Depression
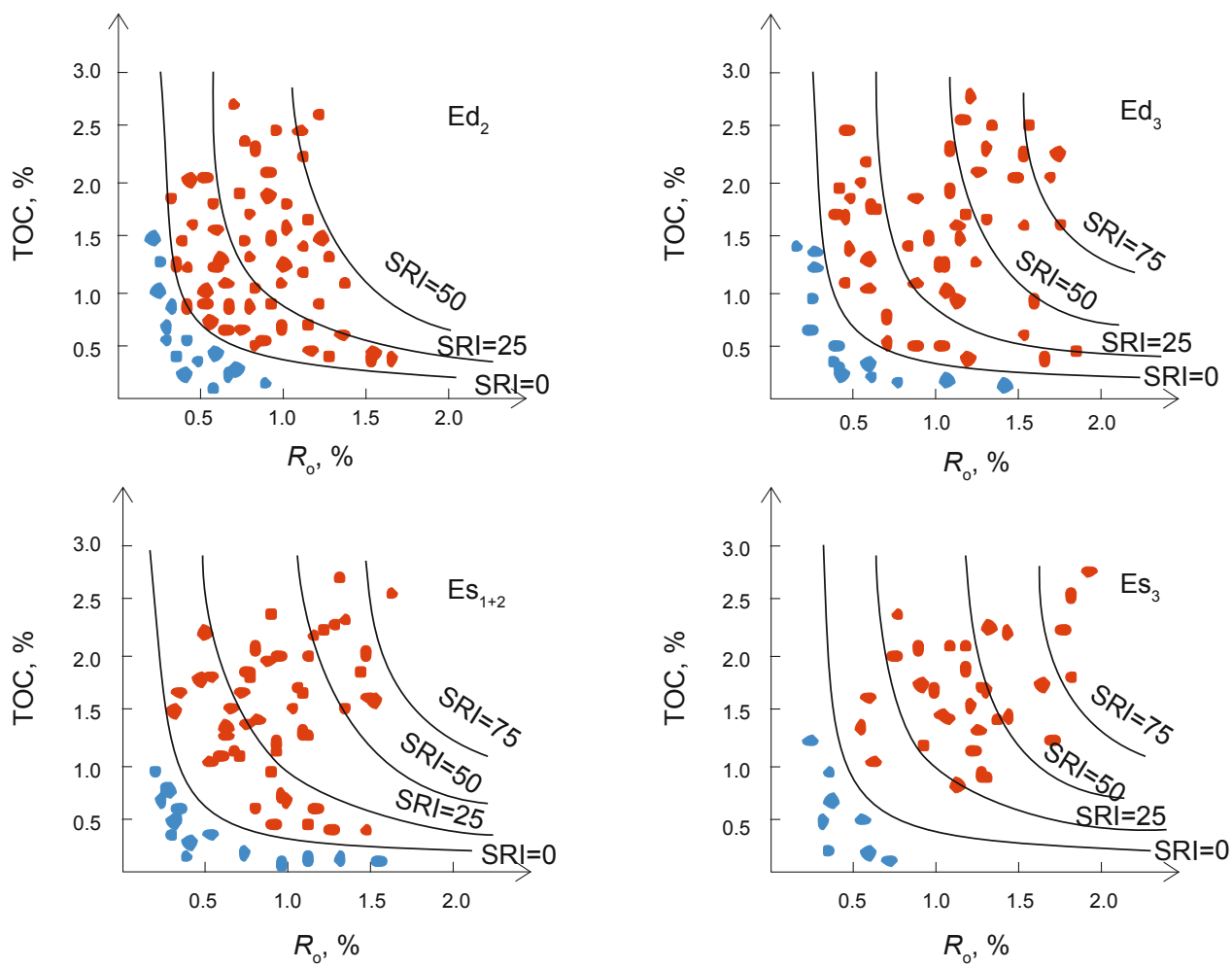

$\mathrm{SRI}<0$, Non-hydrocarbon source rocks; $0-25$, Poor source rocks; 25-50, Medium source rocks; 50-75, Good source rocks; $>75$, Best source rocks

Fig. 4 Identification chart of hydrocarbon expulsion thresholds of source rocks

Table 2 Ratio of effective thickness to dark mudstone thickness of the source rocks in each interval in the Bozhong Depression and its periphery

\begin{tabular}{|c|c|c|c|c|}
\hline \multirow{2}{*}{$\begin{array}{l}\text { Formation } \\
\text { name }\end{array}$} & \multicolumn{3}{|c|}{$\begin{array}{l}\text { Effective thickness/dark mudstone } \\
\text { thickness }\end{array}$} & \multirow{2}{*}{$\begin{array}{c}\text { Number of } \\
\text { exploration } \\
\text { wells }\end{array}$} \\
\hline & $\begin{array}{c}\text { Minimum } \\
\text { value, } \mathrm{m}\end{array}$ & $\begin{array}{c}\text { Maximum } \\
\text { value, } m\end{array}$ & $\begin{array}{l}\text { Average } \\
\text { value, } \mathrm{m}\end{array}$ & \\
\hline $\mathrm{Ed}_{2}$ & 0.32 & 0.77 & 0.68 & 34 \\
\hline $\mathrm{Ed}_{3}$ & 0.37 & 0.89 & 0.75 & 23 \\
\hline $\mathrm{Es}_{1+2}$ & 0.25 & 0.93 & 0.84 & 21 \\
\hline $\mathrm{Es}_{3}$ & 0.65 & 1.00 & 0.92 & 12 \\
\hline
\end{tabular}

From the distribution characteristics of effective source rock, the maximum values of effective thickness of $\mathrm{Ed}_{2}$ and $\mathrm{Ed}_{3}$ are both about $240 \mathrm{~m}$ and mainly located in the deep depression belt of the Bozhong Depression. The effective thicknesses of the members are much less than those of the actual dark mudstone of $700 \mathrm{~m}$ and $750 \mathrm{~m}$. The maximum value of effective thickness of $\mathrm{Es}_{1+2}$ is $280 \mathrm{~m}$, and that of dark mudstone is $550 \mathrm{~m}$, which is almost twice the former. The effective source rock thickness of $\mathrm{Es}_{3}$ is $400 \mathrm{~m}$. Compared with the maximum value of dark mudstone thickness of 550 $\mathrm{m}$, most $(80 \%)$ of the $\mathrm{Es}_{3}$ dark mudstone is effective. 


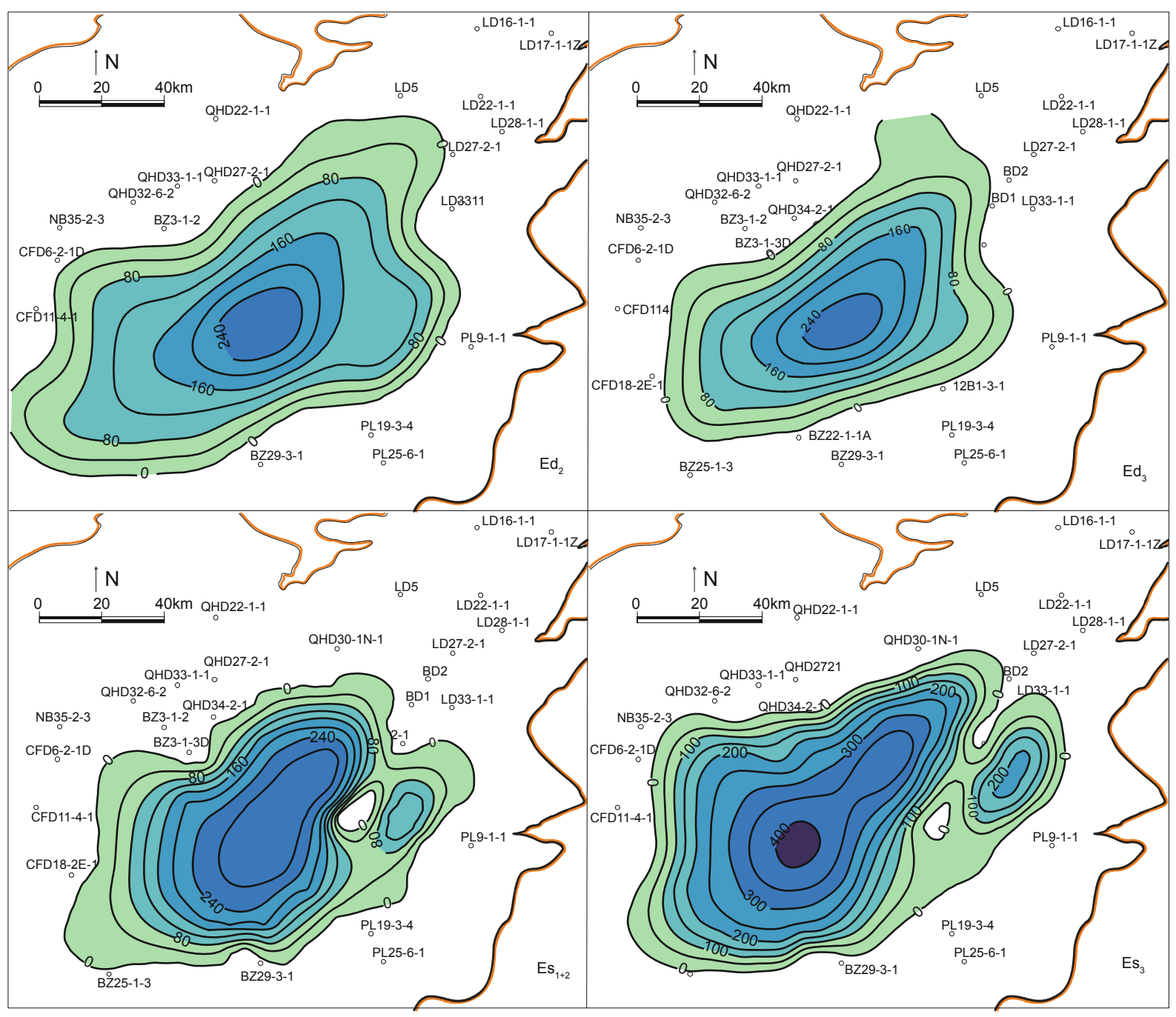

Fig. 5 Contour diagram of effective source rock thicknesses in the Bozhong Depression

\section{Discussion and conclusions}

\subsection{Discussion}

Applying the "two stages and three steps" method to distinguish effective source rocks is simple to operate and various kinds of data are comprehensively used. Relatively the method has a better accuracy compared to the previous methods, however, deficiencies also exist. Firstly, restrained by the scarcity of data, it is hard to apply this method in low-exploration areas. Secondly, in the second step of this method, geochemistry data like pyrolysis data are thoroughly used, which requires rich and evenly distributed analytical information in this area. Thirdly, during the process of mapping planar thickness of effective source rocks, sedimentary facies and organic facies data are required, which is highly affected by operators, so careful thought should be given to ensure the accuracy of results.

\subsection{Conclusions}

1) The "two stages and three steps" method obtained the effective source rock thickness mainly by eliminating the part that was unable to expel hydrocarbon, from the total dark mudstone (oil shale).
2) Four sets of source rocks developed in the Bozhong Depression. These are Member 2 of the Dongying Formation $\left(\mathrm{Ed}_{2}\right)$, Member 3 of the Dongying Formation $\left(\mathrm{Ed}_{3}\right)$, Member 1 -Member 2 of the Shahejie Formation $\left(\mathrm{Es}_{1+2}\right)$ and Member 3 of the Shahejie Formation $\left(\mathrm{Es}_{3}\right)$ in Paleogene. The ratio of effective source rocks to dark mudstone is between $30 \%$ and $80 \%$, while the Member 3 of the Shahejie Formation $\left(\mathrm{Es}_{3}\right)$ has the highest ratio.

3) The "two stages and three steps" method is a practical and accurate technique for predicting effective source rocks.

\section{References}

Barker C. Pyrolysis techniques for source rock evaluation. AAPG Bulletin. 1974. 58(2): 267-294

Bertrand P, Lallier V E and Boussafir M. Enhancement of accumulation and anoxic degradation of organic matter controlled by cyclic productivity: A model. Organic Geochemistry. 1994. 22(3-5): 511520

Carroll A R and Bohacs K M. Lake-type controls on petroleum source rock potential in nonmarine basins. AAPG Bulletin. 2001. 85(6): 1039-1053

Chen A D. Definition and abundance threshold of marine source rocks developed in South China. Petroleum Exploration and Development. 2005. 32(2): 23-25 (in Chinese) 
Chen A D, Huang J M, Yang Z W, et al. Discussions on origin of carbonaceous asphalt in Lower Paleozoic strata in southern Anhui and western Zhejiang and on marine efficiency source rocks in southern China. Marine Origin Petroleum Geology. 2004. 9(1-2): 77-83 (in Chinese)

Cheng K M. Quantity assessment of oil source rock. In: China Land Facies Oil and Gas Generation. Beijing: Petroleum Industry Press. 1982. 175-188 (in Chinese)

Derenne S, Largeau C and Brukner W A. Origin of variations in organic matter abundance and composition in a lithologically homogeneous maar-type oil shale deposit. Organic Geochemistry. 2000. 31(9): 787-798

England W A, Mackenzie A S, Mann D M, et al. The movement and entrapment of petroleum fluids in the subsurface. Journal of the Geological Society London. 1987. 144(2): 327-347

Fu J M, Wang B S, Shi J Y, et al. Evolution of organic matter and origin of sedimentary ore deposits (1) - Origin and evaluation of crude oil and gas. Acta Sedimentologica Sinica. 1983. 1(3): 40-58 (in Chinese)

Gong Z S, Wang G C and He Q. The Neogene: A main realm of hydrocarbon exploration in the Bozhong Sag and its surrounding areas. China Offshore Oil and Gas. 2000. 14(3): 145-156 (in Chinese)

Hou G T, Qian X L and Cai D S. Space-time relationship between tectonics and sedimentation of Meso-Cenozoic Bohai Basin. Oil \& Gas Geology. 2000. 21(3): 201-206 (in Chinese)

Hunt J M. Petroleum Geochemistry and Geology. San Francisco: Freeman and Company. 1979. 5-24

Jiang F J, Pang X Q, Jiang Z X, et al. Hydrocarbon-expulsion characteristics and the potential resource evaluation of hydrocarbon source rocks from the upper section of $4^{\text {th }}$ member of the Shahejie Formation in the Dongying Depression. Geological Science and Technology Information. 2007. 26(2): 69-74 (in Chinese)

Jiang Z X, Pang X Q, Jin Z J, et al. Threshold control over hydrocarbons and its application in distinguishing valid source rock. Earth Science-Journal of China University of Geosciences. 2002. 27(6): 689-695 (in Chinese)

Jin Q. Importance and research about effective hydrocarbon source rocks. Petroleum Geology and Recovery Efficiency. 2001. 8(1): 1-4 (in Chinese)

Jin Q, Zha M and Zhao L. Identification of effective source rocks in the Tertiary evaporite facies in the western Qaidam Basin. Acta Sedimentologica Sinica. 2001. 19(1): 125-129 (in Chinese)

Jones R W. Some mass balance and geological restraints on migration mechanisms. AAPG Bulletin. 1981. 65(1): 103-122

Lewan M D and Williams J A. Evaluation of petroleum generation from resinite by hydrous pyrolysis. AAPG Bulletin. 1987. 71(2): 207-214

Leythaeuser D, Schaefer R G and Radke M. Geochemical effects of primary migration of petroleum in Kimmeridge source rocks from Brae field area, North Sea. I: Gross composition of $\mathrm{C}_{15+^{-}}$ soluble organic matter and molecular composition of $\mathrm{C}_{15+}$-saturated hydrocarbons. Geochimica et Cosmochimica Acta. 1988. 52(6): 701713

Li J, Jiang Z S, Luo X, et al. Discussion on quantitative evaluation criterion for high-mature carbonate gas source rocks. Oil \& Gas Geology. 1999. 20(4): 354-356 (in Chinese)

Li X C. Study on effective hydrocarbon source rocks and relationship between them and natural gas reservoirs. Natural Gas Geoscience. 2003. 14(1): 53-56 (in Chinese)

Momper J A. Oil migration limitations suggested by geological and geochemical considerations. AAPG Bulletin. 1978. 62(3): B1-B60

Pang X Q. Quantitative Simulation of Geological Process. Beijing: Petroleum Industry Press. 2003. 202-208 (in Chinese)

Pang X Q. Theory and Application of Hydrocarbon Expulsion Controlling Petroleum Accumulation. Beijing: Petroleum Industry
Press. 1995. 178-184 (in Chinese)

Pang X Q, Qiu N S and Jiang Z X. Quantitative Simulation of Hydrocarbon Accumulation. Beijing: Petroleum Industry Press. 2005. 194-198 (in Chinese)

Rao D, Zhang P L and Qiu Y Y. Discussion on lower limit of content of organic matter for effective source rocks. Petroleum Geology and Experiment. 2003. 25(Sup.): 578-581 (in Chinese)

Sheng Z W. The problem of effective source rocks. Petroleum Geology and Experiment. 1989. 11(1): 7-15 (in Chinese)

Teng G E, Liu W H, Xu Y C, et al. Correlative study on parameters of inorganic geochemistry and hydrocarbon source rocks formative environment. Advances in Earth Science. 2005. 20(2): 193-200 (in Chinese)

Teng G E, Liu W H, Xu Y C, et al. The discrimination of effective source rock of Ordovician marine facies deposition in Ordos Basin. Progress in Natural Science. 2004. 14(11): 1249-1256 (in Chinese)

Tissot B P and Welte D H. Petroleum Formation and Occurrence: A New Approach to Oil and Gas Exploration. New York: Springer-Verlag. 1978. $125-170$

Wang X Z and Wang X J. Hydrocarbon expulsion mechanism research of source rocks. In: Research of Oil and Gas Generation and Accumulation Model. Beijing: Petroleum Industry Press. 1999. 5193 (in Chinese)

Wang Y S, Jin Q, Zhu G Y, et al. Characterization of the effective source rocks in the Shahejie Formation of the Jiyang Depression. Petroleum Exploration and Development. 2003. 30(3): 53-55 (in Chinese)

Xia X Y and Dai J X. A critical review on the evaluation of hydrocarbon potential of marine carbonate rocks in China. Acta Petrolei Sinica. 2000. 21(4): 36-41 (in Chinese)

Xiong Y Q. The application of GC-IRMS associating thermal simulation experiment in research of effective source rock. Ph.D Thesis. Guangzhou Geochemistry Institute of China Academy of Sciences. 2001. 11-55 (in Chinese)

Zhang G C. Tectonic framework and prolific hydrocarbon depressions in Bohai Bay. China Offshore Oil and Gas. 2000. 14(2): 93-99 (in Chinese)

Zhang Y, Wang P J, Chen W L, et al. Effective source rock identification and application-Case of the Tarim Basin. Petroleum Geology \& Oilfield Development in Daqing. 2006. 25(6): 9-12 (in Chinese)

Zhang Y, Wang P J, Chen W L, et al. Identification and mapping of the effective source rocks-Taking the Kongquehe area of the Tarim Basin as an example. Journal of Jilin University (Earth Science Edition). 2007. 37(3): 463-468 (in Chinese)

Zhou G J and Zhang F H. Research of quantitative model of organic material evolution-Description of lower mature $\mathrm{Es}_{4}$ source rock in the Dongying Depression south slope. In: Research of Oil and Gas Generation and Accumulation Model. Beijing: Petroleum Industry Press. 1999. 10-50 (in Chinese)

Zhou J and Pang X Q. A method for calculating the quantity of hydrocarbon generation and expulsion. Petroleum Exploration and Development. 2002. 29(1): 24-27 (in Chinese)

Zhu G Y and Jin Q. Study on source rock heterogeneity - a case of Niu38 well in Dongying Depression. Acta Petrolei Sinica. 2002. 23(5): 34-39 (in Chinese)

Zhu G Y, Jin Q and Wang R. Identification methods of effective source rocks. Journal of China University of Petroleum. 2003. 27(2): 6-10 (in Chinese)

Zhu W L and Ge J D. Gas exploration potential in the offshore Bohai Bay Basin. Acta Petrolei Sinica. 2001. 22(2): 8-13 (in Chinese)

Zhu W L, Wang G C and Zhou Y. Potential of petroleum resources in the offshore Bohai Bay Basin. Acta Petrolei Sinica. 2000. 21(3): 1-7 (in Chinese)

(Edited by Hao Jie) 